\title{
The 2015 Gorkha Earthquake and response of the Kathmandu Valley sediments
}

\author{
*Sudhir Rajaure ${ }^{1}$, Megh Raj Dhital ${ }^{2}$, Lalu Prasad Paudel ${ }^{2}$ \\ ${ }^{1}$ Department of Mines and Geology, Nepal \\ ${ }^{2}$ Central Department of Geology, Tribhuvan University, Nepal \\ *Email:srajaure@gmail.com
}

\begin{abstract}
The Gorkha Earthquake occurred on the gently dipping part of the Main Himalayan Thrust (MHT), close to the Main Central Thrust (MCT). This earthquake possibly occurred in the source zone of the 1833 Nepal Earthquake (Mw 7.6), which occurred after 182 years. The region between the 1905 Kangra Earthquake and 1934 Bihar-Nepal Earthquake has not produced any great earthquake since the last 500 years and still remains a potential site for great earthquake(s) in future. The Kathmandu Valley witnessed moderate ground acceleration and comparatively large velocity as recorded at Kantipath during the Mw 7.8, Gorkha Earthquake. The analysis of the records show that high frequencies were damped and low frequencies were dominant over the sedimentary basin, which can be attributed to the response of the sediments underneath. Because of damping of high frequencies, the engineered, low storey buildings were less damaged and resisted the ground shaking comparatively well. However, on the other hand, the historical monument 'Dharahara' collapsed completely and the high rise apartment buildings suffered more because of the dominance of low frequencies.
\end{abstract}

Keywords: Peak ground acceleration, predominant period, high frequency, low frequency and damping

Received: May 20, 2015

Revision accepted: June 25, 2015

\section{INTRODUCTION}

The Himalayan Range is an active collisional orogen, which is about $2400 \mathrm{~km}$ long. It falls in the boundary between the Indian Tectonic Plate and the Eurasian Tectonic Plate. The Indian Tectonic Plate is moving towards north at an average velocity of about $4 \mathrm{~cm}$ a year relative to Eurasia (e.g. Bettinelli et al. 2006). Approximately half of this convergence is absorbed across the Himalaya in straining the crust and resulting in the accumulation of elastic stress in the region. The accumulated elastic stress is released in the form of earthquakes, when the elastic stress exceeds the strength of surrounding rock. Large earthquakes occur less frequently but are capable to cause unimaginable loss of lives and property. It is a cyclic process, because after the release of accumulated energy by large earthquakes, accumulation of energy starts again for next large earthquake right after. Small earthquakes occur frequently but do not contribute much to release the stored elastic energy; therefore large earthquakes are inevitable to release the energy in time and again.

In the last century, the Himalaya hosted four destructive earthquakes, which are the 1897 Shillong Earthquake (Mw 8.1), 1905 Kangra Earthquake (Mw 7.8), 1934 Bihar-Nepal Earthquake (Mw 8.1) and 1950 Assam Earthquake (Mw 8.5) (Ambraseys and Douglas 2004, Seeber and Armbruster 1981, Khattri 1987, Molnar 1990, Molnar and Pandey 1989, Hough and Bilham 2008, Yeats and Lillie 1991, Yeats et al. 1992). The region between the 1934 Bihar-Nepal Earthquake (Mw 8.1) and the 1905 Kangra Earthquake (Mw 7.8) has been reported not to have produced any great earthquake since the last five hundred years. This stretch of the Himalaya has been termed as seismic gap (Khattri 1987, 1992, Bilham et al. 1995), which is suspected as the site of next great destructive earthquake in the region in future. It should be noted that any earthquake source region has a maximum magnitude potential, which depends on the size (area and length) of the source zone but there is probability of smaller $(\mathrm{Mw}<8.0)$ earthquakes (e. g. Kramer 2008) and therefore smaller earthquakes may also occur.

Nepal occupies about one-third arc length of the Himalaya. It falls in a seismically high hazard zone (e. g. Thapa and Wang 2013), which has been reported to have experienced many destructive earthquakes in its written history. Since 1255 , the Kathmandu Valley has been reported to have experienced five major destructive earthquakes in 1225, 1408, 1681, 1833 and 1934. The magnitudes of these earthquakes are estimated to be more than 7.5 (Chitrakar and Pandey 1986, Bilham et al. 1995, Pandey et al. 1995, Hough and Bilham 2008). Among these, the $1934 \mathrm{Mw} 8.1$ Bihar-Nepal earthquake is the most destructive one, which claimed more than 10,700 lives in Nepal and adjoining part of India. This earthquake had a maximum intensity of MMI X in the Kathmandu Valley, which destroyed about $19 \%$ and damaged about $38 \%$ of the buildings in the valley (Pandey and Molnar 1988, Rana 1935). The 18 September 2011 earthquake has been felt in six countries, i.e. Bangladesh, Bhutan, China, India, Pakistan and Nepal, causing the death toll of more than 100 people in the region (Thapa and Wang 2013). The last great earthquake of 1934 is still in the 
living memory of elder people. This earthquake claimed about 4296 (e. g. Pandey and Molnar 1988) lives in Kathmandu Valley only. Documented records of destruction reveal that the Kathmandu Valley has experienced many destructive earthquakes in the past (e.g. Chitrakar and Pandey 1984).

Similar reports of past destructive earthquakes from the western part of Nepal are not available. An Mw 8.5 earthquake reportedly destroyed the western part of Nepal along with the adjoining part of south Tibet and north India (Bilham et. al. 2004). Thus, the region in western Nepal, between Gorkha and Dehradoon of India was anticipated to host great earthquake(s). In contrary to the anticipation, the Gorkha Earthquake (Mw 7.8) occurred in the region, which is believed to have hosted the 1833 Nepal Earthquake ( Mw 7.6, Bilham). Thus, this earthquake can be considered as a repeat of the 1833 (Mw 7.6) Nepal Earthquake. The rupture of the the earthquake did not propagate towards west and the energy stored in that region, which is known as a 'seismic gap', is not released, therefore the threat of great earthquake(s) in the west of Gorkha remains unchanged.

\section{Previous Works}

The response of the Kathmandu Valley was first studied by Pandey (2004). He used relative power spectra of ambient noise recorded at 60 soil sites with reference to that recorded at rock site in the Kathmandu Valley. He reported that the amplified predominant frequency is at $2 \mathrm{~Hz}$ and the amplification factor ranges between 12 and 15. Similarly there are other peaks of amplification in the frequency range between 0.6 and $5 \mathrm{~Hz}$, but the amplification factor varies across the valley. The amplification factor is about 5 to 6 in the lacustrine area, between 2 to 3 in transitional area and between 1 and 2 in fluviatile area.

Paudyal et al. (2012) applied horizontal-to-vertical ratio of Fourier spectra (H/V ratio technique) of ambient noise recorded at soil sites to estimate fundamental frequency at different parts of the Kathmandu Valley. They reported that the valley has fundamental frequencies in the range between 0.6 to $8.9 \mathrm{~Hz}$ in the central and northern part of the sedimentary basin. In addition to the fundamental frequency, they report other peaks between 4 and $6 \mathrm{~Hz}$ in the central and northern part of the sedimentary basin.

Rajaure et al. (2014) investigated the response of the Kathmandu Valley sediments using ground acceleration data recorded in the Kathmandu Valley. It is the first investigation of its kind in the Kathmandu Sedimentary basin, which used acceleration data recorded at four soil sites and one rock site. They used the ground acceleration data of the 30 August 2013, South-Tibet Earthquake (M4.9) recorded at five sites in the Kathmandu valley. They evaluated the site response function as ratio of Fourier amplitude spectrum at soil site with reference to that at a rock site. The response of the soil sites are found remarkably similar in the low frequency domain $(<0.8 \mathrm{~Hz})$, whereas variation in response can be noticed above $0.8 \mathrm{~Hz}$. The prominent variation exists at frequencies larger than $2 \mathrm{~Hz}$, which is in consistence with the variation of PGA across the valley implying the shallow depth geology is inhomogeneous. The earthquake was a smaller one and the variation of PGA across the valley has been interpreted as the response of shallow sedimentary layers, which possibly varies laterally across the valley.

\section{Gorkha Earthquake}

The Kathmandu Valley and other northern districts between Gorkha (in the west) and Dolakha (in the east) were violently shaken by the 12 April 2015 Gorkha (Mw 7.8, USGS) Earthquake. This is the largest earthquake after the 1934 BiharNepal Earthquake to hit Nepal. The earthquake occurred at 06:11:46 (UTC) in the morning and according to the National Seismological Centre (NSC) of Department of Mines and Geology (DMG), the earthquake occurred at $28.24^{\circ} \mathrm{N}$ latitude and $84.75^{\circ} \mathrm{E}$ longitude with focal depth at $15 \mathrm{~km}$. The Seismic network of the Department of Mines and Geology has recorded the earthquake and its aftershocks very well. The distribution of aftershocks (source: www.seismonepal.gov.np) and the fault plane solutions (source: www.isc.ac.uk ) depict that the Gorkha Earthquake (Mw 7.8) and the 26 April aftershock (Mw 6.9) occurred on east-west trending, low angle thrust fault (Fig. 1).

This Gorkha earthquake and its aftershocks have caused massive destruction in the region between Gorkha and Dolakha. The epicenter of this earthquake falls in the western part of Gorkha District, at a distance of about $80 \mathrm{~km}$ from the Kathmandu Valley. This earthquake was followed by a number of aftershocks in which three aftershocks were strong ones. The first aftershock of Mw 6.5 occurred on 25 April, which is close to the the main shock. The second aftershock (Mw 6.9) occurred on 26 of April in Dolakha District at about $80 \mathrm{~km}$ in the north-east direction from the Kathmandu Valley and the strongest aftershock (Mw 7.3) occurred on 12 May at about $80 \mathrm{KM}$ in the north-east from the Kathmandu Valley. Based on the distribution of aftershocks (Fig. 1) the Gorkha Earthquake ruptured an area of about $150 \mathrm{~km}$ in the east-west direction and $40 \mathrm{~km}$ in the north-south direction. The Gorkha Earthquake and its aftershocks have claimed more than 8500 lives officially.

\section{Ground Motion Parameters}

Peak ground acceleration is a high frequency characteristic of ground motion. The observed accelerations during the Gorkha Earthquake are smaller than what was expected and therefore the intensity of this earthquake is comparatively low. The epicentral intensity of this earthquake is about VIII and the intensities in the Kathmandu Valley are only about VI to VII. The peak ground acceleration (PGA) recorded at Kantipath (USGS site) is about $182.5 \mathrm{~cm} / \mathrm{sec}^{2}$ (Fig. 2a) on the vertical component and on the horizontals it's even smaller. However, on the other hand, the velocity is comparatively large (Fig. 2b). Velocity is a low frequency characteristic of the ground motion and is an important parameter for flexible type structures (tall buildings). 


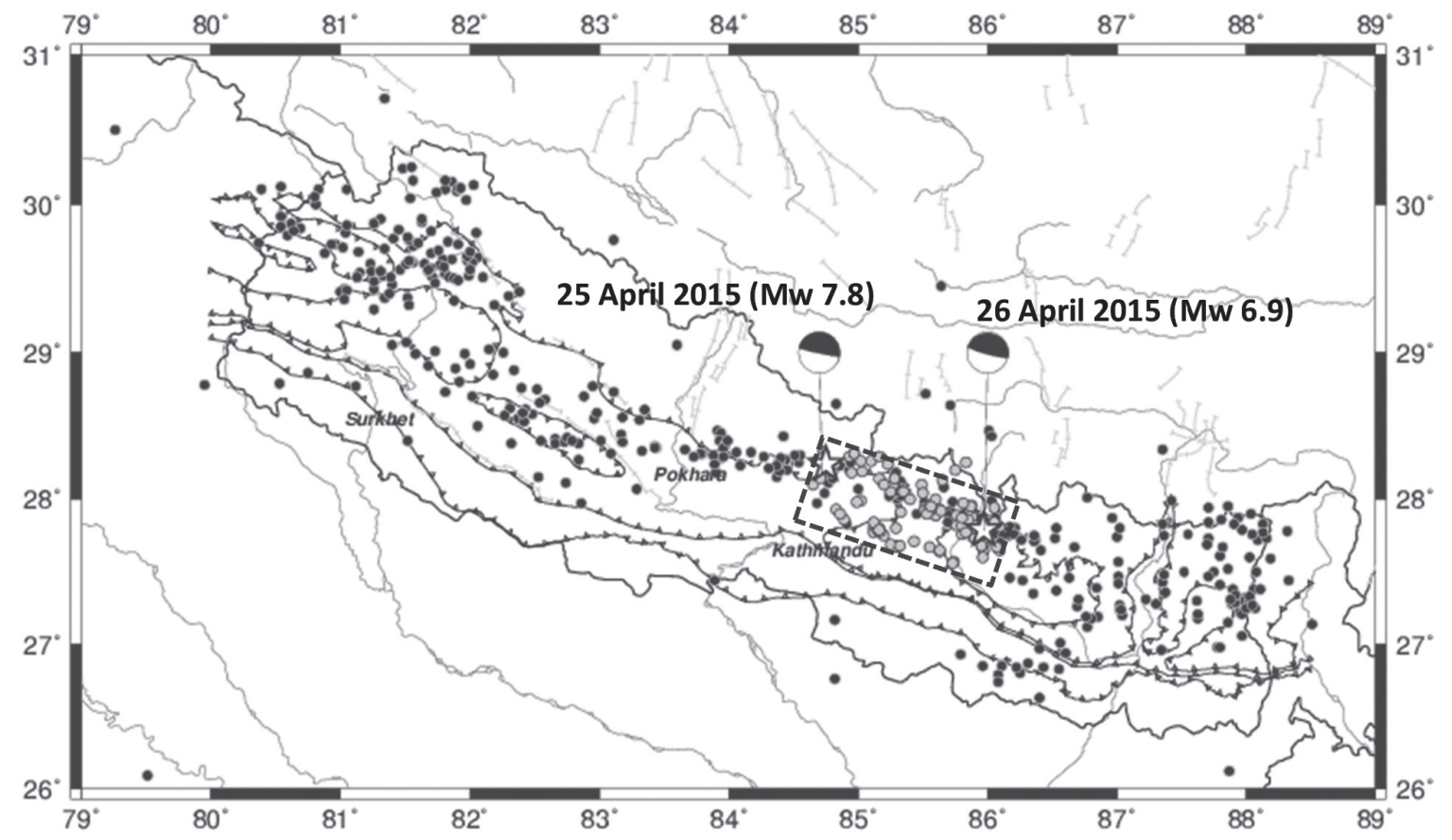

Fig. 1: The Gorkha earthquake (white star at the left), its strong aftershock (Mw 6.9) at the right (white star) and the aftershocks (grey solid circles) which occurred by 30th of April. The black circles are the ML $>4.0$ earthquakes released by the National Seismological Centre of Department of Mines and Geology (1994-2014). The black dashed rectangle is the inferred rupture area of the Gorkha Earthquake. Fault plane solutions are from the International Seismological Centre (UK).

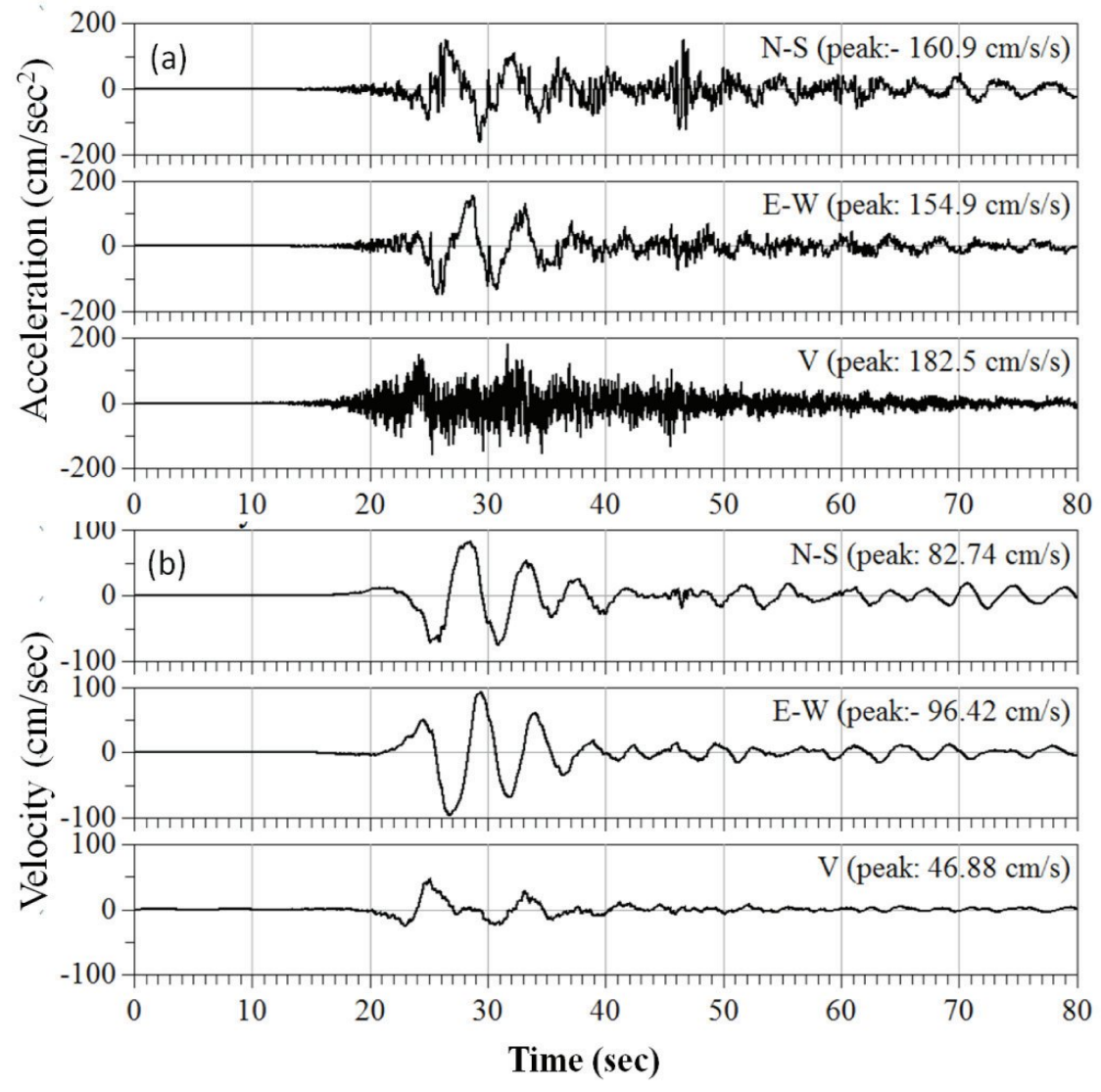

Fig. 2: Ground acceleration (a) and velocity (b) recorded at Kantipath. The maximum peak ground acceleration is observed on the vertical component, whereas the maximum peak ground velocity is observed on the east-west component. 
A Fourier amplitude spectrum depicts how the amplitudes are distributed with frequencies (or period) in the ground motion. Fig. 3(a) depicts the distribution of amplitudes with frequency at the Kantipath site and reveals that the high frequencies were damped and low frequencies were dominant. The predominant frequency of the ground motion at Kantipath is about $0.2 \mathrm{~Hz}$. In addition to the peak at $0.2 \mathrm{~Hz}$, two more peaks are noticed at $0.6 \mathrm{~Hz}$ and $1.25 \mathrm{~Hz}$ in the spectra (Fig. 3a).

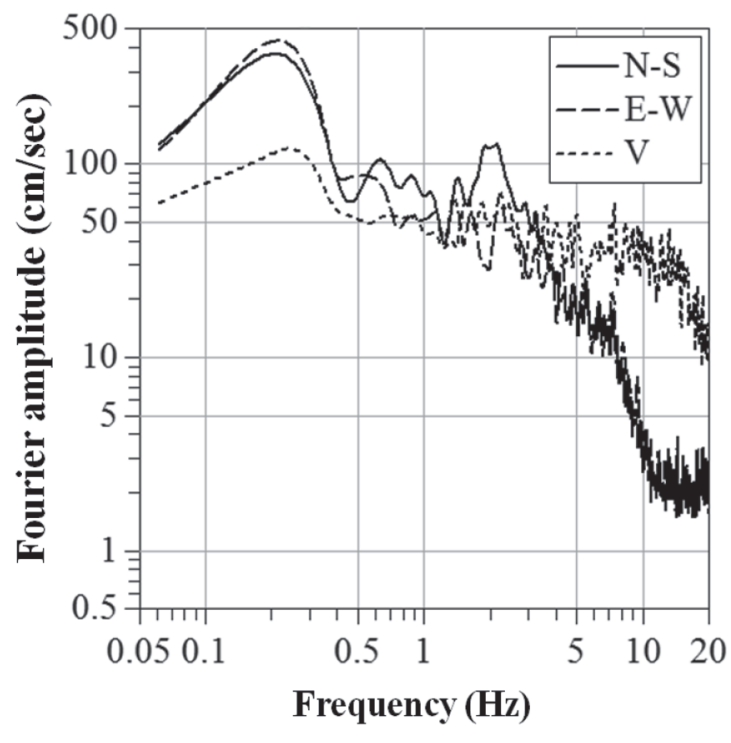

(a)

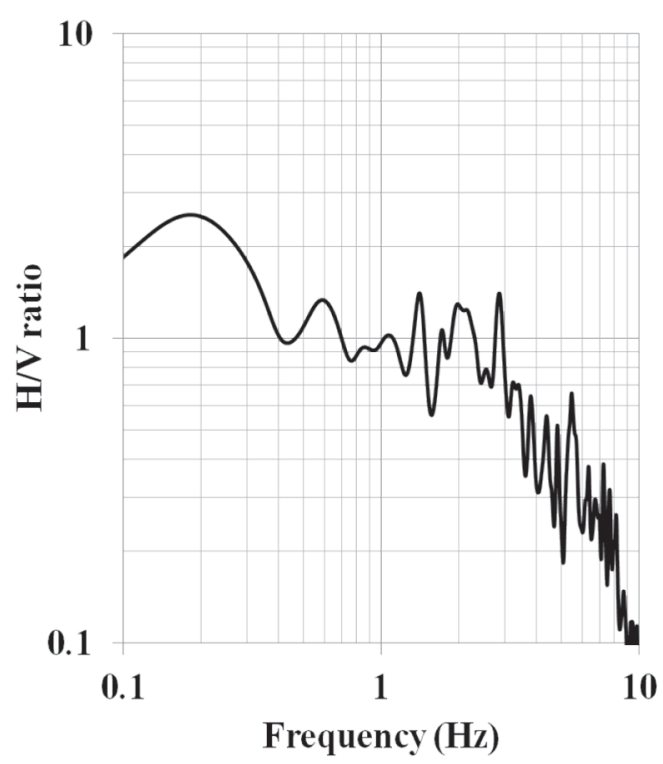

(b)

Fig. 3: Fourier amplitude spectra of the ground motion at the Kantipath site (a) and H/V ratio of the ground motion (b). The predominant frequency of the ground motion is about $0.2 \mathrm{~Hz}$.

The ratio of Fourier spectrum of horizontal component to that of the vertical component (known as $\mathrm{H} / \mathrm{V}$ ratio) at a soil site is commonly used to estimate the fundamental frequency of the ground. This technique is commonly used to estimate fundamental frequency of soil site using ambient ground noise. In this study, the $\mathrm{H} / \mathrm{V}$ ratio technique is applied to earthquake data recorded at the Kantipath site. Here, the $\mathrm{H} / \mathrm{V}$ ratio is calculated using the following formula.

$$
\mathrm{H} N \text { ratio }=\frac{\sqrt{\mathrm{F}_{\mathrm{NS}^{2}} \mathrm{~F}_{\mathrm{EW}}{ }^{2}}}{\mathrm{~F}_{\text {Vertical }}}
$$

Where, $F_{N S}, F_{E W}$ and $F_{V}$ stand for the Fourier amplitude of north-south, east-west and vertical components of the ground motion, at the corresponding frequencies, respectively.

The $\mathrm{H} / \mathrm{V}$ ratio of the earthquake data recorded at Kantipath is presented in Fig. 3(b). The figure shows that the fundamental frequency of the ground is about $0.2 \mathrm{~Hz}(5 \mathrm{Sec})$. The fundamental frequency of the ground closely correlates with the predominant frequency of the ground motion.

\section{DISCUSSION AND CONCLUSIONS}

Great earthquake was anticipated in the region, west of Gorkha District based on historical records of earthquakes and paleoseismic investigation in the region. However, the Gorkha Earthquake occurred in the region which is believed to have produced the 1833, Nepal Earthquake. Therefore, the threat of great earthquake in the west of Gorkha remains unchanged.

The Gorkha Earthquake occurred on a gently dipping part of the Main Himalayan Thrust beneath the Gorkha District. It ruptured an area of about $150 \mathrm{~km}$ in the east-west direction and $40 \mathrm{~km}$ in north south direction. The rupture of the earthquake did not propagate towards west of the epicenter, possibly, because a major transverse structure exists close to the epicenter as can be noticed in the result by Pandey et al. (1999) and Rajaure et al. (2013), where the NW-SE, trending seismicity belt is offset.

The Kathmandu Valley is underlain by thick succession of sedimentary layers. During the Gorkha Earthquake, the recorded peak ground acceleration was smaller than expected, however the velocity was relatively large. Peak ground acceleration is a high frequency characteristic of ground motion, which is an important parameter to rigid structures (small storey structures). During the Gorkha Earthquake, high frequencies were damped and therefore majority of the small storey structures survived the ground shaking. On the other hand, the peak ground velocity is a low frequency characteristic of ground motion and is an important parameter to the flexible structures (tall buildings). The damage to tall buildings correlates well with the large peak ground velocity.

The fundamental frequency of the Kantipath site is about $0.2 \mathrm{~Hz}$. Similarly, there are two other peaks at $0.5 \mathrm{~Hz}$ and 1.5 
$\mathrm{Hz}$, respectively. The peak at $0.2 \mathrm{~Hz}$, observed in this study, is not noticed in the report of Paudyal et. al. 2012. The peaks at $0.2 \mathrm{~Hz}$ and $0.5 \mathrm{~Hz}$ possibly represent the basin response, whereas the peak at $1.5 \mathrm{~Hz}$ represents the response of shallow sedimentary layer. Multiple resonant frequencies at the site implicate the possibility of resonance at different frequencies

The results presented here correspond to the Kantipath site, which is a soil site and is in the middle part of the Kathmandu Valley. The geology of the Kathmandu Valley is highly variable and its response could be, different at different places accordingly. A thorough investigation of ground response in the Kathmandu Valley would be very helpful to revise building code, strengthen existing structures of historical values and would pave a way for land use planning in the Kathmandu Valley.

\section{ACKNOWLEDGEMENTS}

We express sincere thanks to the United States Geological Survey (USGS) for the installation of its accelerometer in Kathmandu at Kantipath. Similarly, We would like to thank the Strong Motion Centre (www.strongmotioncenter.org) for making the acceleration data available to everyone. We are also thankful to all the officials of the National Seismological Centre, Nepal who, despite their very hard time, processed and delivered the result of aftershock location on the website.

\section{REFERENCES}

Ambraseys, N. N. and Douglas, J., 2004, Magnitude calibration of north Indian earthquakes. Geophys. Jour. Int., v. 159, pp.165-206. doi:10.1111/j.1365-246X.2004.02323.x.

Bettinelli, P., Avouac, J. P., Mireille, F., Jouanne, F., Bollinger, L., Wills, P. and Chitrakar, G. R., 2006, Plate motion of India and interseismic strain in the Nepal Himalaya from GPS and DORIS measurements. Journal of Geodesy. doi: 10.1007//s00190-006-0030-3.

Bilham, R., 2004, Earthquakes in India and the Himalaya: tectonics, geodesy and history. Ann. Geophys., v. 47 pp. 839-858. doi:10.4401/ag-3338.

Bilham, R., 1995, Location and Magnitude of the 1833 Nepal Earthquake and its Relation to the Rupture zones of Contiguous Great Himalayan earthquakes. Current Science, v. 69(2), pp. 155-187.

Bilham, R., Bodin, P. and Jackson, M. 1995, Entertaining a great earthquake in western Nepal; Jour. Nepal Geol. Soc., v. 11(1), pp. 73-78.

Bilham, R., Gaur, V. K. and Molnar, P., 2001, Himalayan Seismic Hazard, Science, v. 293.

Chitrakar, G. R. and Pandey, M. R., 1986, Historical earthquakes of Nepal. Jour. Nepal Geol. Soc., v. 4(1), pp. 7-8.
Department of Mines and Geology (DMG), Seismic data, 19952014 (www.seismonepal.gov.np), Kathmandu, Nepal.

Hough, S. E. and Bilham, R., 2008, Site Response of the Ganges Basin Inferred from Re-evaluated Macroseismic Observations from the 1897 Shillong 1905 Kangra and 1934 Nepal Earthquakes. Jour. Earth System and Sci., v. 117, pp. 773-782.

International Seismological Centre. Focal mechanism data, http://www.isc.ac.uk, Internatl. Seis. Cent., Thatcham, United Kingdom.

Khattri, K. N., 1987, Great earthquakes, seismicity gaps and potential for earthquake disaster along the Himalaya Plate boundary. Tectonophysics, v. 138, pp. 79-92.

Khattri, K. N., 1992, Seismic Hazard in Indian Region. Current Sci., v. 62, pp. 109-116.

Kramer, S. L., 2008, Geotechnical Earthquake Engineering. Pearson Education, $653 \mathrm{p}$.

Pandey, M. R. and Molnar, P., 1988, The distribution of intensity of the Bihar-Nepal Earthquake of the 15 January 1934 and bounds on the extent of the rupture zone. Jour. Nepal Geol. Soc., v. 5(1), pp. 22-44.

Pandey, M. R., Tandukar, R. P., Avouac, J. P., Vergne, J. and Heritier, T., 1999, Seismotectonics of the Nepal Himalaya from a local seismic network. Jour. Asian Earth Sci., v. 17, pp. 703-712.

Pandey, M. R., 2000, Ground Response of Kathmandu Valley on the basis of microtremors. 12WCEE, 2000 (unpublished).

Paudyal, Y. R., Bhandary, N. P. and Yatabe, R. 2012, Seismic Microzonation of Densely Populated Area of Kathmandu Valley of Nepal using Microtremor Observations. Journal of Earthquake Engineering, v. 16(8), pp. 1208-1229.

Rajaure, S., Koirala, B., Pandey, R., Timsina, C., Jha, M., Bhattarai, M., Dhital, M. R., Paudel, L. P. and Bijukchhen, 2014, Ground response of the Kathmandu Sedimentary Basin with reference to 30 August 2013 South-Tibet Earthquake. Jour. Nepal Geol. Soc., v. 47, pp. 23-44.

Rajaure, S., Sapkota, S. N., Adhikari, L. B., Koirala, B., Bhattarai, M., Tiwari, D. R., Gautam, U., Shrestha, P., Maske, S., Avouac, J. P., Bollinger, L., and Pandey M. R., 2013, Double difference relocation of local earthquakes in the Nepal Himalaya. Jour. Nepal Geol. Soc., v. 46, pp. 133-142.

Thapa, R. and Wang, G., 2013, Probabilistic seismic hazard analysis in Nepal. Earthquake Eng. and Eng. Vibration, v. 12(4), pp. 577-586.

Molnar, P., 1990, A review of the Seismicity and the Rates of active underthrusting and te deformatation at the Himalaya. 
Jour. Himalayan Geol., v. 1, pp. 131-154.

Molnar, P., and Pandey, M. R., 1989, Rupture zones of great earthquakes in the Himalayan Region. Proc. Indian Acad. Sci. (Earth Plan. Sci.), v. 98, pp. 61-70.

Yeats, R. S. and Lillie, R. J., 1991, Contemporary tectonics of the Himalayan frontal fault system: folds blind thrusts and the 1905 Kangra earthquake. Jour. Stru. Geol., v. 13, pp. 215-225.

Yeats, R. S., Nakata, T., Farah, A., Fort, M., Mirza, M. A., Pandey, M. R. and Stein, R. S., 1992, The Himalayan Frontal Fault Sytem. Annales Tectonicae, v. 6, (Sp. Issue) pp. 85-98. 